summarizes the most important achievement of this remarkable man, who was born in a shepherd's cottage on Eskdale, became the first president of the Institution of Civil Engineers and a Fellow of the Royal Society and was buried in Westminster Abbey. The exhibition will remain open to the public on weekdays between 9.30 a.m. and 5 p.m. (12.30 p.m. on Saturdays) until July 15, except for the period June 24-29. There is no charge for admission.

\section{Archæology in South Africa}

ONCE again the annual report of the Archæological Survey in South Africa, for the period. April 1, 1954March 31, 1955 (Union of South Africa : Department of Education, Arts and Science. Pp. 8. Pretoria : Government Printer, 1956), shows considerable activity. Not only has work continued in the Makapan valley, where so many of the recently discovered re mains of ape-men have been found, but also in the Pietersburg district. A picture of the archæology of the Central Transvaal has now been built up. Further work at Mapungubwe has been undertaken, and archæological sites in the vicinity of Krausberg, Muden and Weenen visited, where new rock paintings were discovered. Two other publications of the South African Department of Education, Arts and Science report archæological investigations in East Griqualand and Mapungubwe. In East Griqualand, industries belonging to the Fauresmith culture (first intermediate), the Middle Stone Age-early and late, the Magosian culture (second intermediate) and the Later Stone Age have been found. In "A Preliminary Account of the Archæology of East Griqualand", by B. D. Malan (Archæological Series No. 8. Pp. $14+10$ plates. Pretoria : Government Printer, 1955. 10s.) details of the finds at a number of sites are given, with some good illustrations.

The account of "The Glass Beads of Mapungubwe" will be among the last of the articles by the late Dr. C. Van Riet Lowe to be published (Archæological Series No. 9. Pp. 22. Pretoria : Govermment Printer, 1955. 18s.). Mapungubwe is a small, flat-topped, sandstone hill on the farm Greefswald in the northern Zoutpansberg district, and is situated on the south bank of the Limpopo River. Excavations have been in progress at the site since 1933 and much interesting material has been discovered. More than one people occupied the site at different times. Dating, in such circumstances, is always somewhat problematical. There are clearly connecting links with Zimbabwe, but Mapungubwe, especially in its later phases, can be much later in date, possibly even belonging to the seventeenth or early eighteenth centuries of our era. The account of the glass beads found adds much to our knowledge, and the inclusion of a plate in colour is very valuable. Beads are somewhat unsatisfactory objects for the archæologist to deal with. They have a great survival potentiality, and are therefore not very useful for accurate dating, and they may often have been transported from great distances. It seems possible that the East Indies were in early times a considerable source of beads which later found their way to East Africa, and thence into the interior of the continent.

\section{Lundy Field Society}

THE tenth annual report of the Lundy Field Society contains a heartening record of progress both in the financial and scientific spheres which should encourage the Society in its future activities. Besides the usual bird list, the report contains an account by $H$. J. Boyd of the biology of guillemots and razorbills as shown by ringing observations on the island over the period 1947-56. The same author has examined records of the gull populations over the same ten-year period; these show a steady decline in the numbers of great and lesser blackbacks and wide fluctuation in the numbers of kittiwakes. Barbara Whitaker describes results obtained from shag ringing between 1948 and 1955 and analyses the weights and measurements of certain migrant species which were trapped on the island. A description of a prehistoric settlement at Garret's Combe is contributed by K. S. Gardner. Copies of the report may be obtained from the secretary, Prof. L. A. Harvey, of the University of Exeter, price $5 s$.

\section{Photoperiodic Control of Cambial Activity}

Ax investigation of the effect of photoperiodic conditions on cambial activity in secdlings of Robinia pseudoacacia by P. F. Wareing and D. L. Roberts (New Phytol., 55, 356 ; 1956) has yielded some new and interesting facts. The seedlings were first exposed to short-day conditions in order to bring about the cessation of extension-growth. If such seedlings were continued under short-day conditions for several weeks, the cambium of the stem also ceased activity. On the other hand, if the seedlings were transferred to long-day conditions after extension-growth had stopped, cambial activity was maintained in approximately half the plants. The maintenance of cambial activity depends upon exposure of the leaves to long-day conditions. In bark-ringing experiments it was shown that the cambial stimulus, which apparently originates in the leaves, is transported in a basipetal direction in the stem. The maintenance of cambial activity under long-day conditions is not accompanied by any detectable bud-growth. The new wood formed under long-days after extensiongrowth has ceased is of the 'summer-wood' type. The vessels in such wood appear to arise from the region in which the leaf-traces join the main vascular system of the stem. These results suggeat that a cambial stimulus may arise in the mature leaves under long-day conditions, and that meristematic activity at the shoot apices is not a necessary condition for cambial activity.

\section{Zoological Nomenclature}

THE International Commission on Zoological Nomenclature gives notice that, as from December 28,1957 , it will start voting on the following cases involving the possible use of its plenary powers for the purposes specified against each entry. Full details of these cases were published on June 28 in the Bulletin of Zoological Nomenclature (13, Parts 6 and 7): (1) musicus Linnaeus, 1758 (Turdus), suppression ; iliacus Linnaeus, 1758 (Turdus), validation of neotype for (Cl. Aves); (2) Oeobia Hubner, [1825], and emend. Oebia, suppression (CI. Insecta, Order Lepidoptera); (3) Indiana Matthew, 1902, designation of type species for (Cl. Crustacea, Order Ostracoda) ; (4) Globigerinidae Carpenter, Parker and Jones, 1862 , to be given precedence over Orbulinidae Schultze, 1854 (Cl. Rhizopoda, Order Foraminifera); (5) Labeceras Spath, 1925, designation of type species for (Cl. Cephalopoda, Order Ammonoidea); (6) Calycoceras Hyatt, 1900, designation of type species for (Cl. Cephalopoda, Order Ammonoidea); (7) Hoplitoplacenticeras, validation of, as from Paulcke, 1906, with Hoplites plasticus Paulcke, 1906, as type species (Cl. Cephalopoda, Order Ammonoidea) ; (8) Kotoceras 